\title{
Isolation and Characterization of Twenty-four Microsatellite Loci for Rhododendron decorum Franch. (Ericaceae)
}

\author{
Xue-qin Wang ${ }^{\mathbf{1}}$ \\ Key Laboratory of Biodiversity and Biogeography, Kunming Institute of \\ Botany, Chinese Academy of Sciences, Kunming 650204, Yunnan, China; \\ and Graduate School, Chinese Academy of Sciences, Beijing 100039, China
} Yuan Huang ${ }^{1,2}$

Key Laboratory of Biodiversity and Biogeography, Kunming Institute of Botany, Lanhei Road 132, Kunming 650204, Yunnan, China

\section{Chun-lin Long}

Key Laboratory of Biodiversity and Biogeography, Kunming Institute of Botany, Chinese Academy of Sciences, Kunming 650204, Yunnan, China; and College of Life and Environmental Sciences, Minzu University of China, Beijing 100081, China

Additional index words. Rhododendron decorum, microsatellite, genetic diversity

\begin{abstract}
Rhododendron decorum is a common species in southwest China and northeast Myanmar, in which the flowers have been eaten as a favorite vegetable. We isolated and characterized 24 microsatellite primer pairs from this species. The number of alleles ranged from two to seven. The observed and expected heterozygosities $\left(H_{O}\right.$ and $\left.H_{E}\right)$ were 0.3830 to 0.7855 and 0 to 0.7917 , respectively. Eleven loci were significantly deviated from Hardy-Weinberg equilibrium as a result of the heterozygote deficiency. Cross-species amplification in another eight Rhododendron species showed their potential use for evolutionary and conservation studied in this genus. These markers will be useful to reveal the genetic population structure and genetic diversity of $R$. decorum.
\end{abstract}

Rhododendron L. is a large and diverse genus with a nearly worldwide distribution, and the center of diversity of the genus is in the Himalayas (Kron and Judd, 1990). This genus contains seven subgenus in all, including Hymenanthes, which has 23 subsections with $\approx 270$ species (Fang et al., 2005), and all the species are diploids $(2 \mathrm{n}=26)$ (Min and Fang, 1990). Most species in subgenus Hymenanthes are world-famous ornamental plants as a result of the evergreen leaves and large and colorful flowers (Min, 1984). Rhododendron decorum belongs to subgenus Hymenanthes. It is a beautiful evergreen shrub or small tree, commonly distributed in southwest China and northeast Myanmar (Fang et al., 2005). Its flower is a favorite edible vegetable for local ethnic people in

Received for publication 27 July 2009. Accepted for publication 20 Aug. 2009.

This work was supported by the Ministry of Science and Technology of China (2008FY110400-2-2 and 2005DK21006), the Ministry of Education of China (B08044 and CUN-985-3-3), and the Japan Society for the Promotion of Science (JSPS/AP/109080).

Ms. Dong-mei Rui joined in field work to collect samples.

${ }^{1}$ Both authors contributed equally.

${ }^{2}$ To whom reprint requests should be addressed; e-mail long@mail.kib.ac.cn. southwest China (Yong and Chong, 1980). In common with other species of subgenus Hymenanthes, $R$. decorum is highly interfertile, which was supported by molecular evidence (Zha et al., 2008; Zhang et al., 2007). However, until now, little research has been conducted related to population genetics of $R$. decorum. To study more deeply the genetic diversity within this species and the effect of hybridization on the speciation process of this species, we developed 24 microsatellite markers for this species to investigate the genetic diversity and genetic structures among populations and provide a potential tool for studying molecular breeding in $R$. decorum.

Genomic DNA was extracted from leaf tissues using the cetyltrimethyl ammonium bromide method (Milligan, 1992). Approximately 300 ng genomic DNA was completely digested with $\mathrm{Mse}$ I restriction enzyme (Fermantas). The digested DNA was ligated to the MseI adaptor pair (Vos et al., 1995), then $5 \mu \mathrm{L}$ of the adapter-ligated fragments acted as templates to perform polymerase chain reaction (PCR) in a volume of $20 \mu \mathrm{L}$ using MseI-N ( $5^{\prime}$-GAT GAG TCC TGA GTA AN$\left.3^{\prime}\right)$ as the primer and following the program: $95^{\circ} \mathrm{C}$ for $3 \mathrm{~min}, 30$ cycles of $94^{\circ} \mathrm{C}$ for $30 \mathrm{~s}$, $53{ }^{\circ} \mathrm{C}$ for $60 \mathrm{~s}, 72{ }^{\circ} \mathrm{C}$ for $60 \mathrm{~s}$, followed by $72{ }^{\circ} \mathrm{C}$ for $5 \mathrm{~min}$.
For enrichment, the PCR products were denatured at $95{ }^{\circ} \mathrm{C}$ for $5 \mathrm{~min}$, then hybridized with a $5^{\prime}$-biotinylated probe (AG) 15 in 250 $\mu \mathrm{L}$ hybridization solution $(20 \times \mathrm{SSC}, 10 \%$ SDS, $100 \mathrm{pmol} / \mu \mathrm{L}$ probe) at $48{ }^{\circ} \mathrm{C}$ for $2 \mathrm{~h}$. The DNA hybridized to the probe was separated and captured by streptavidin-coated magnetic beads at room temperature for $20 \mathrm{~min}$, followed by two washing steps, including three times in $\mathrm{TEN}_{100}$ for $15 \mathrm{~min}$ and three times in $\mathrm{TEN}_{1000}$ for $24 \mathrm{~min}$. The separated single-stranded DNA was subjected to a second round of PCR according to the same procedure as the first round of PCR. The PCR products, after being purified with the E.Z.N.A Gel Extraction Kit (Omega Bio-Tek, Atlanta, GA), were ligated into PMD18-T vector (TaKaRa) according to the manufacturer's instructions and then transformed into Escherichia coli strain JM109 (Sangon, Shanghai). The positive clone was picked out by blue-white screening and tested by PCR using (AG) 10 and $\mathrm{M}^{+} 3^{+}$

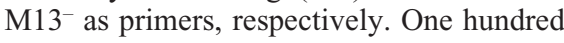
ten of 292 screened clones contained potential microsatellite motifs.

A total of 50 clones were found to contain simple sequence repeats and then subjected to primer designing using the Primer 5.0 (Clarke and Gorley, 2001). Twenty-four individuals from two wild populations, two semicultivated and cultivated populations, were used to screen polymorphism. PCR reaction was done in $20 \mu \mathrm{L}$ volume using a PTC0200 thermal cycler (MJ Research, Ashland). Each reaction was performed using $20 \mathrm{ng}$ of genomic DNA, $1 \mu \mathrm{M}$ of each dNTP, $1 \mu \mathrm{M}$ each primer, $1 \times$ Taq buffer [100 mm Tris- $\mathrm{HCl}, \mathrm{pH} 8.8,2.0 \mathrm{~mm} \mathrm{MgCl}_{2}$, $200 \mathrm{~mm}\left(\mathrm{NH}_{4}\right)_{2} \mathrm{SO}_{4}, 0.1 \%$ Tween 20$]$ and $1 \mathrm{U}$ of Taq polymerase (TaKaRa). The PCR programs took place as follows: initial denaturing step at $95^{\circ} \mathrm{C}$ for $5 \mathrm{~min}, 30$ cycles of $94^{\circ} \mathrm{C}$ for $30 \mathrm{~s}$, primer-specific annealing temperature 55 to $62{ }^{\circ} \mathrm{C}$ for $30 \mathrm{~s}, 72^{\circ} \mathrm{C}$ for $30 \mathrm{~s}$, and a final extension step at $72{ }^{\circ} \mathrm{C}$ for $8 \mathrm{~min}$. The PCR products were electrophoresed in denaturing $6 \%$ polyacrylamide gels using a 25-bp DNA ladder molecular size standard (Fermantas) to estimate allele size by silver staining.

Of the 50 new primers designed for $R$. decorum, 32 successfully amplified the target regions and 24 of them displayed polymorphism. The number of alleles per locus, observed $\left(H_{O}\right)$ and expected heterozygosity $\left(H_{E}\right)$, and deviation form Hardy-Weinberg equilibrium (HWE) were assessed using GENEPOP Version 3.4 (http://wbiomed.curtin. edu.au/genepop/) (Raymond and Rousset, 1995). The number of alleles per locus ranged from two to seven with an average of 4.1 (Table 1). The observed and expected heterozygosities $\left(H_{O}\right.$ and $\left.H_{E}\right)$ ranged from 0.3830 to 0.7855 and from 0 to 0.7917 with averages of 0.6121 and 0.4531 , respectively. Among the 24 microsatellite markers, 11 loci show significant deviation from HWE $(P<$ 0.01 , Table 1 ), probably as a result of deficiency of heterozygote or the limitation of sample size. Tests for linkage disequilibrium 


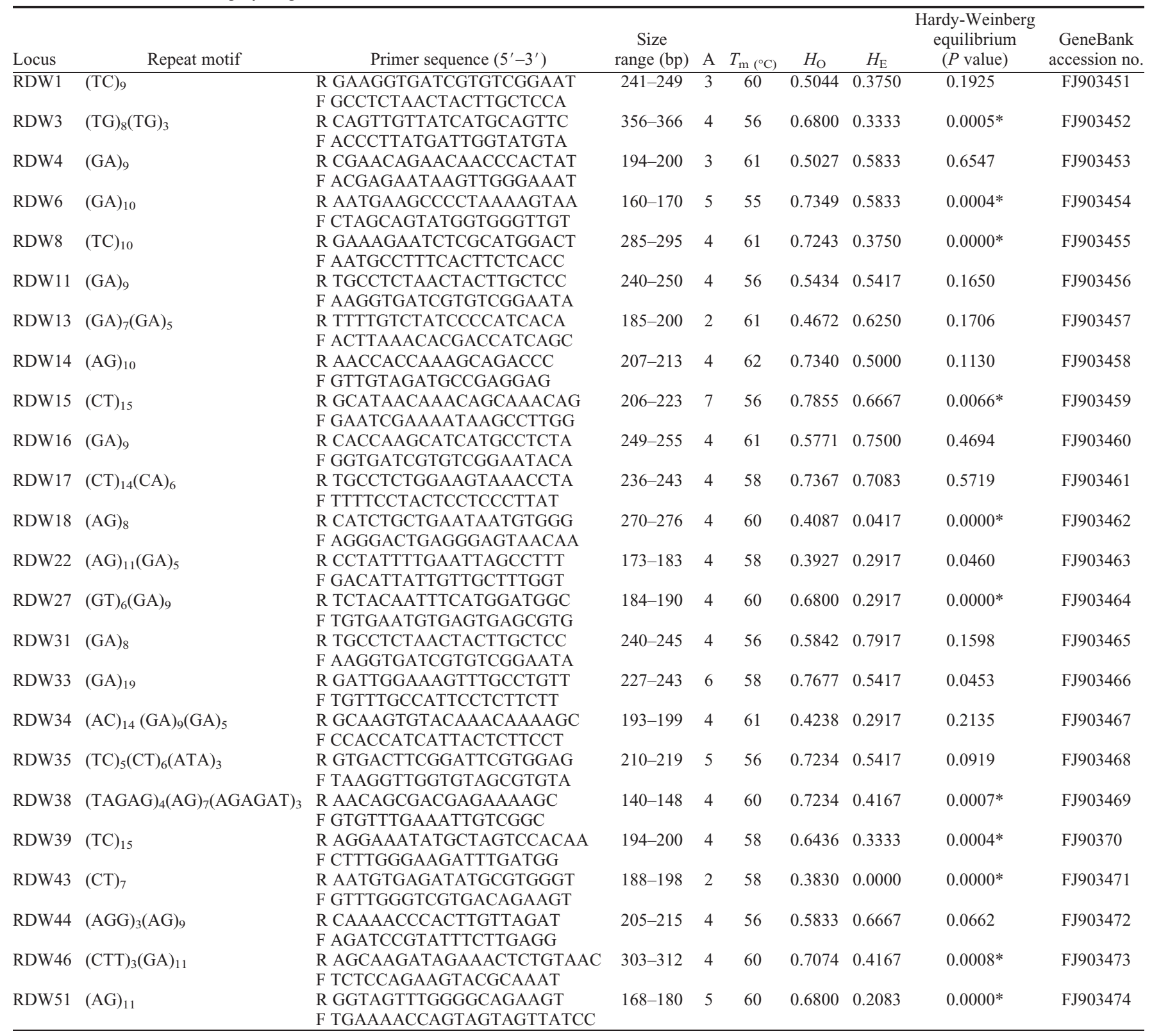

$\mathrm{Tm}=$ annealing temperature of primer pair; $\mathrm{A}=$ number of alleles; $\mathrm{H}_{\mathrm{o}}=$ observed heterozygosity; $\mathrm{H}_{\mathrm{E}}=$ expected heterozygosity. Statistically significant deviation from Hardy-Weinberg expectation is indicated by the asterisk $(P<0.01)$.

were run in FSTAT Version 2.9.3.2 (Goudet, 1995). Significance levels were adjusted using sequential Bonferroni corrections (Rice, 1989). No loci showed significant linkage disequilibrium after Bonferroni correction. For cross-species application, these 24 new primer pairs were tested in the other eight important horticultural species and close taxa such as $R$. irroratum, $R$. agastum, $R$. delavayi, $R$. araiophyllum, $R$. molle, $R$. simsii, $R$. pachypodu, and $R$. spinuliferum. Twelve pairs of them can be amplified successfully in all species, whereas the RDW18 failed amplification in all species (Table 2). These polymorphic microsatellite loci presented here would provide a useful tool for studying the population genetic structure and genetic diversity of $R$. decorum, and it will also be valuable for studying other species in this group.

\section{Literature Cited}

Clarke, K.R. and R.N. Gorley. 2001. PRIMER v5: User manual/tutorial. PRIMER-E Ltd., Plymouth, UK. p. 91.

Fang, M.Y., R.Z. Fang, M.Y. He, L.Z. Hu, H.B. Yang, H.N. Qin, T.L. Min, F. David, P.S. Chamberlain, G.D. Wallace, and A. Anderberg. 2005. Rhododendron (Ericaceae), p. 333. In: Wu, Z.Y. and P.H. Raven (eds.). Flora of China. Vol. 14. Science Press and Missouri Botanical Garden Press, Beijing, China, and St. Louis, MO.

Goudet, J. 1995. FSTAT (Version 1.2): A computer program to calculate F-statistics. J. Hered. $86: 485-486$

Kron, K.A. and W.S. Judd. 1990. Phylogenetic relationship within the Rhodoreae (Ericaceae) with specific comments on the placement of Ledum. Syst. Bot. 15:57-68.

Milligan, B. 1992. Plant DNA isolation. A practical approach, p. 59-88. In: Hoelzel, A.R. (ed.).
Molecular genetic analysis of populations. IRL Press, Oxford, UK.

Min, T.L. 1984. A revision of subgenus Hymenanthes (Rhododendron L.) in Yunnan and Xizang. Acta Botanica Yunnanica 6:141-171.

Min, T.L. and R.Z. Fang. 1990. The phylogeny and evolution of genus Rhododendron. Acta Botanica Yunnanica 12:353-365.

Raymond, M. and F. Rousset. 1995. GENEPOP version 1.2: Population genetics software for exact tests and ecumenicism. J. Hered. 86:248249.

Rice, W.R. 1989. Analyzing tables of statistical tests. Evolution 43:223-225.

Vos, P., R. Hogers, M. Bleeker, M. Reijans, T. Vandeleet, M. Hornes, A. Frijters, J. Pot, J. Peleman, M. Kuiper, and M. Zabeau. 1995. AFLP: A new technique for DNA fingerprinting. Nucleic Acids Res. 23:4407-4414.

Yong, J. and L.S. Chong. 1980. Rhododendrons of China. Binford \& Mort, Portland, OR. p. 307. 
Table 2. Cross-species amplification of 24 new microsatellite loci from Rhododendron decorum in other related Rhododendron species.

\begin{tabular}{|c|c|c|c|c|c|c|c|c|}
\hline Locus (species) & R. irroratum & R. agastum & R. delavayi & R. araiophyllum & R. molle & R. simsii & R. pachypodum & R. spinuliferum \\
\hline RDW1 & $t^{z}$ & + & + & + & + & + & + & + \\
\hline RDW4 & + & - & + & + & - & + & - & + \\
\hline RDW6 & + & + & + & + & + & - & + & + \\
\hline RDW11 & + & + & + & + & + & + & + & + \\
\hline RDW13 & + & - & + & - & - & - & - & + \\
\hline RDW14 & + & + & + & + & + & + & + & + \\
\hline RDW17 & + & + & + & + & + & + & + & + \\
\hline RDW18 & - & - & - & - & - & - & - & - \\
\hline RDW22 & + & + & - & + & - & - & - & - \\
\hline RDW27 & - & + & + & + & + & + & + & + \\
\hline RDW31 & + & + & + & + & + & + & + & + \\
\hline RDW33 & + & + & + & + & + & + & + & + \\
\hline RDW34 & - & - & + & - & - & - & - & - \\
\hline RDW46 & + & + & + & + & + & + & + & + \\
\hline RDW51 & + & + & + & + & + & - & - & + \\
\hline
\end{tabular}

${ }^{\mathrm{z}}$ The plus symbols $(+)$ indicate successful polymerase chain reaction (PCR) amplification and the minus symbols (-) suggested failed PCR amplification.

Zha, H.G., R.I. Milne, and H. Sunday. 2008. Morphological and molecular evidence of natural hybridization between two distantly related Rhododendron species from the Sino-
Himalaya. Bot. J. Linn. Soc. 156:119129.

Zhang, J.L., C.Q. Zhang, L.M. Gao, J.B. Yang, and H.T. Li. 2007. Natural hybridization origin of
Rhododendron agastum (Ericaceae) in Yunnan, China: Inferred from morphological and molecular evidence. J. Plant Res. 120:457463 